\title{
LA PERCEPCIÓN DE LA REALIDAD NTERNACIONAL EN EL JOVEN ORTEGA (1883-1907)
}

\author{
Juan Pablo Camazón Linacero*
}

\begin{abstract}
RESUMEN
José Ortega y Gasset es el filósofo español más importante del siglo

$X X$. Su pensamiento internacional ha sido poco estudiado. Este trabajo lo aborda en la primera etapa de su vida, hasta 1907 en que concluye su formación. Las ideas del joven Ortega surgen en ambientes muy contradictorios: de un lado, entre liberales y jesuitas; de otro, entre la decadencia española y una Alemania in crescendo.

\section{PALABRAS CLAVE}

Catolicismo, colonialismo, cosmopolitismo, decadencia, elitismo, Europa, nación.
\end{abstract}

\begin{abstract}
ABSTRAC
José Ortega y Gasset is the most important spanish philosopher in the $X X$ century. His international idea has been studied scarcely. This work treats it in the first period of his life, until 1907 when he ended his formation. The young Ortega's ideas spring in very contrary ambients: on the one hand, between liberals and jesuits; on the other hand, between the spanish fall and a Germany in crescendo.
\end{abstract}

\section{KEYWORDS}

Catholicism, colonialism, cosmopolitism, elitism, Europe, fall, nation.

La vida internacional es una realidad compleja. Así es porque en ella confluyen múltiples factores, de diversa índole: políticos, geográficos, económicos, culturales, religiosos. Los diferentes actores internacionales, con el Estado a la cabeza pero sin olvidar las organizaciones internacionales, los movimientos sociales transnacionales, el mismo individuo, desarrollan sus relaciones en el marco de una gran variedad de circunstancias. Multiplicidad

\footnotetext{
* En la actualidad se encuentra redactando El pensamiento político internacional de Ortega y Gasset en el periodo de entreguerras (1919-1939), tesis doctoral dirigida por Ángeles Egido León, Departamento de Historia Contemporánea, UNED. El presente trabajo es una adaptación de parte del primer capítulo.
} 
que, a su vez, posibilita distintos puntos de vista, desde donde proyectar otras tantas perspectivas, individuales y en grupo, para observar, entender y valorar esa realidad. Un fenómeno complicado que exige un cierto grado de desarrollo intelectual; colectivamente, requiere un avanzado estado de evolución histórica. Ha de haber un comienzo. Cabe preguntarse cómo y cuándo empieza en el hombre la percepción de la realidad internacional. Sin olvidar una cuestión que, aún elemental y primaria, no deja de ser capital: cuál es el contenido de esa realidad.

Por fortuna, la enorme riqueza de la obra de José Ortega y Gasset (1883-1955) facilita responder en particular a la cuestión planteada. No se pretende una contestación abstracta, más bien histórica y biográfica. No fue un internacionalista, pero sí un espectador atento a la realidad de su tiempo. ¿Es posible que este incansable observador del entorno no participara en la reflexión sobre el llamado problema de España o en la polémica casticismoeuropeísmo? Ante un siglo de la historia plagado de conflictos coloniales, totalitarismos, guerras devastadoras... en fin, ante los grandes acontecimientos y retos políticos de la primera mitad del siglo XX ¿cabe pensar que Ortega, espectador máximo donde los hubiere, ignorara estas cuestiones?. $Y$ el resultado final de su reflexión ¿será una serie de ideas inconexas o un pensamiento coherente?

Tuvo que haber unos momentos iniciales de toma de contacto con la realidad internacional, a datar en los años de infancia y juventud, situarlos en el ambiente familiar y en la formación recibida hasta 1907, cuando regresa de su estancia estudiantil en Alemania. Si no fuera confiados por la capacidad de observación expresada en la correspondencia, los primeros artículos y el componente autobiográfico de los textos posteriores, el asunto quedaría tan irresoluto como vano el intento. Una buena disculpa para adentrarnos en la vida y obra de Ortega desde otra perspectiva y, la vez, ensayar una respuesta concreta a la pregunta del principio, tan severa en apariencia.

\section{ÁFRICA Y AMÉRICA DE MI NIÑEZ}

Algunos datos de la historia familiar de Ortega no pueden obviarse para situar el ambiente «internacional» en el que se desarrolla su infancia. El abuelo paterno José Ortega y Zapata (1824-1903), funcionario y periodista, estuvo destinado en Cuba, donde nació el padre del pensador ${ }^{1}$. El otro abuelo, Eduardo Gasset y Artime (1832-1884) sentó las bases políticas y periodísticas de la familia al fundar El Imparcial en 1867. En 1870 fue nombrado subsecretario de Estado y, en junio de 1872, ministro de Ultramar; dimitió seis meses después por la cuestión de la abolición de la esclavitud. Le sucedió su hijo Rafael Gasset en la dirección de El Imparcial, dando conti-

ORTEGa Spottorno, José, Los Ortega. Madrid, Taurus, 2002. págs. 3-9. 
nuidad a la línea liberal-reformista y democrática; fue diputado por Santiago de Cuba en 1892. El padre del filósofo, José Ortega Munilla (1856-1922), se había incorporado a El Imparcial en 1878 y hacia 1900 asume la dirección del rotativo.

Desde sus comienzos, El Imparcial prestó una gran atención a los acontecimientos internacionales, tales como la guerra franco-prusiana, la Comuna de París o la Internacional. Rafael Gasset convirtió el rotativo en forjador de opinión pública mediante campañas de prensa acerca de temas como la pésima política naval. Organizó campañas humanitarias por calamidades públicas o con ocasión de la guerra Las noticias desde el exterior ganaban espacio y coadyuvaron al incremento de la tirada del periódico. La línea editorial aceptaba los hechos consumados y apoyó patrióticamente a las tropas sin soslayar, por ello, una severa crítica a la política de Madrid².

Ortega disfrutó de la biblioteca de su padre, repleta de clásicos castellanos y literatura francesa. Él y su hermano mayor, Eduardo, ingresaron en el Colegio de San Estanislao de Kostka en Miraflores del Palo (Málaga). Allí cursó el bachillerato de 1891. a 1897. El curso siguiente, se trasladó al Centro de Estudios Superiores de Deusto donde cursó primero de un programa conjunto de Filosofía y Letras y Derecho. Ambos centros estaban regidos por la Compañía de Jesús. Ortega aprovechó bien la formación recibida a juzgar por sus notas. Años después, a propósito del comentario al libro de Ramón Pérez de Ayala A.M.D.G., rememoró su posición de «emperador» con la que los jesuitas distinguían a los alumnos más brillantes. Que agregara que «mis afaries democráticos acaso no sean otra cosa que una manera del despecho ${ }^{3}$, ha de interpretarse como una reacción al signo antiliberal de la pedagogía jesuítica.

Fuera de esperar, en consecuencia, una educación rígidamente católica y elitista de acuerdo al postulado ignaciano del magis, «el más». La excelencia marcaba el estilo. En Málaga recibió las primeras lecciones de Historia Universal bajo el magisterio del padre Gonzalo Coloma, muy apreciado por Ortega. Asistía a sus clases con sumo placer para escuchar su brillante oratoria ${ }^{4}$. El tratamiento oral y los textos manejados no diferirían mucho de la visión providencialista de la Historia tal y como se impartía en el resto de los colegios confesionales. Aunque daban importancia a la Historia Antigua, hacia el cambio de siglo se apercibieron de la fuerza aleccionadora de la Historia nacional en el amor a la patria. La narración construía la nacionalidad

\footnotetext{
${ }^{2}$ CoBo, Eugenio, Eduardo Gasset y Artime. Biografía de un pontevedrés ilustre. A Coruña, Edicios do Castro, 1996. págs. 59-90, 99-125 y 129-144; SÁNCHEZ ILLÁN, Juan Carlos, Prensa y política en la España de la Restauración. Rafael Gasset y El Imparcial. Madrid, Editorial Biblioteca Nueva, 1999. págs. $29-39$.

${ }^{3}$ ORTEga y Gasset, José, Obras Completas. Madrid, Alianza Editorial, 1994, (1ª edición en Alianza Editorial, $2^{a}$ reimpresión), 12 vols. Vol. I, pág. 532.

“ Ortega Spottorno, José, «Niñez y Mocedad de Ortega», Revista de Occidente, 228, 2000. págs. $142-153$.
} 
propia en oposición a las identidades francesa, la revolucionaria, e inglesa, la imperialista. Las lecciones culminaban en el Siglo de Oro; el XVIII fue el de la decadencia y la extranjerización, el pasado más reciente, ignorado. El método recurría a la repetición mecánica y pasiva de fechas y acontecimientos e, incluso, ejercitaban la representación teatralizada de episodios, facilitando así un salto de la realidad histórica a la leyenda ${ }^{5}$.

Por otra parte, en la formación del joven Ortega se aprecia el gusto por la lengua francesa. A los once años, en una carta remitida a sus padres en noviembre de 1894, dice que «el Francés es muy fácil y ya vamos bastante adelantados ${ }^{6}$. En el resto de la correspondencia infantil lo utiliza cada vez más, hasta llegar a párrafos completos.

El 20 de febrero de 1893, con nueve años, escribe una carta ${ }^{7}$ en la que transmite a sus padres las primeras impresiones «internacionales» que podían percibirse en un internado católico, a saber, la actividad misionera. En este aspecto, los jesuitas habían escrito capítulos decisivos en la historia y teología coloniales desde las reducciones guaraníes en el Paraguay barroco a la «inculturación» más contemporánea. Ajeno a tan severas cuestiones, mas inmerso en un ambiente evangélico, comenzaba el relato epistolar así: «han formado los padres de la compañía algunos pueblos...»; luego reproducía, con la inocencia propia de la niñez, la narración de un misionero a lo largo de un día de vacación en el campo: el sacerdote en la lejana misión, el indio huérfano y enfermo, la solución final gracias a la caridad cristiana y la medicina. Una percepción de la realidad internacional tamizada por el pensamiento cristiano: providencialista, mesiánica e idealizada.

A pesaí de un internado que le alejaba de cualquier otra realidad que no fuera la del colegio, las vivencias y la atmósfera en torno a la guerra de África marcaron la infancia del niño. Los mismos textos de madurez certifican esa preocupación. Los recuerdos de la aventura colonial española en Marruecos recuperan la imagen del colegial:

«Es desmesurada, es irritante la influencia que sobre mi generación ha tenido el vocablo Melilla. Cuando yo tenía ocho o nueve años y estudiaba en un colegio de jesuitas, abierto sobre las playas malagueñas, vi una tarde pasar soldados que iban a África. Era la primera guerra de Melilla, que comenzó con la muerte del general Margallo» 8 .

${ }^{5}$ Boyd, Carolyn P., «El pasado escindido: la enseñanza de la Historia en las escuelas españolas, 1875-1900", Hispania LXI/3, núm. 209 (2001), págs. 859-878. Para los centros de la Compañía, REVuELTA González, Manuel, Los colegios de jesuitas y su tradición educativa (1868-1906). Madrid, Universidad Pontificia de Comillas, 1998. págs. 214-215, 480-481, 494-501.

${ }^{6}$ OrTEga y GASSET, José, Cartas de un joven español, Edición de Soledad Ortega. Madrid, Ediciones El Arquero, 1991. pág. 57

${ }^{7}$ lbid. págs.53-54.

${ }^{8}$ Ortega, Obras..., vol. Il, pág. 677. 
El pensador recuerda la visita de un pariente al colegio que le regala un ros y, al «verlo así, convertido en materia cruenta y fúnebre, me produjo horror, y atada al horror quedó para siempre en los sótanos de mi memoria la palabra Melilla» ${ }^{9}$. Ciertamente la guerra con Marruecos despertó su atención. El 8 de noviembre de 1896 comunica entusiasmado a sus padres que en el colegio les están leyendo «la Guerra de África por D. Pedro Ant. Alarcón». El título preciso de la obra, de enorme éxito en su época, fue Diario de un testigo de la guerra de África (1859). La experiencia como voluntario narrada por Alarcón interesó mucho a un Ortega que, aunque referido al estilo literario, manifiesta que «en todo lo que escribo tiendo a obrar bajo su poderoso efecto" 10 .

La política colonial ultramarina tuvo en Ortega mayor peso aún. Cuando el final de siglo aceleró los acontecimientos y agudizó el conflicto, El Imparcial tomó conciencia de la gravedad de los hechos y desplegó para la ocasión una gran actividad. A la vez que Rafael Gasset informaba desde Cuba, su hermano Ramón noticiaba desde Nueva York el apoyo norteamericano ${ }^{11}$. No le sería sencilo a Ortega seguir estas noticias desde el internado, y menos aún disponer del diario. Sin embargo, una carta fechada el 8 de marzo de 1896 prueba lo contrario:

«El artículo semi- cría (sic) «la Beligerancia» creo que no será de papá por varias razones y hay algún párrafo que no hay mas que leerlo para suponer que es del tío Rafael; pero no me quiero meter a juzgar cosas que ni debo ni puedo censurar» ${ }^{12}$.

El artículo en cuestión apareció publicado en El Imparcial a finales de febrero; le sucedieron consecutivamente otros tres bajo el mismo título ${ }^{13}$. El autor anónimo, herido en su patriotismo, noticiaba el reconocimiento norteamericano de la beligerancia de los insurrectos en Cuba. Acaso Ortega se atrevió a opinar sobre la autoría de los escritos teniendo en cuenta la denuncia de escasez de recursos navales, lo cual no podía proceder ya sino de un Rafael Gasset siempre atento a ese tema. No obstante, es digno de subrayar que un adolescente de trece años tuviera entre sus lecturas las noticias internacionales más actuales y que, además, opinara prudentemente sobre ellas.

La pérdida de Cuba y Filipinas sorprendió a Ortega en Deusto. La experiencia resultó traumática en todos los sentidos. Una carta a sus padres de 4

๑ Ibid., pág. 678.

10 Ortega, Cartas..., pág. 75.

"SÁNCHez ILLÁN, op. cit., 1999. págs. 103-106. ORTEGa y GASSET, Manuel, El Imparcial. Biografía de un gran periódico español. Zaragoza, Librería general, 1956. pág. 131-132.

12 Ortega, Carias..., pág. 65.

${ }^{13}$ El Imparcial, 29-|I-1896, 1-|II-1896, 2-II|-1896 y 3-III-1896. 
de diciembre revela que no estaba muy a gusto ni con el clima frío y húmedo a orillas del Nervión, ni con la disciplina espartana de los jesuitas: diana a las 6 de la mañana, misa matutina, aprendizaje diario de las lecciones. "Esto está aburridito», terminó por confesar. Obtuvo buenas calificaciones en los exámenes parciales celebrados en Bilbao y en los finales de Salamanca, pero Derecho no prosperó y terminará por abandonarlo. De estas fechas data la crisis religiosa y su rechazo a los jesuitas ${ }^{14}$. El joven universitario presenció lo que la propia historiografía jesuita ha calificado como «quiebra disciplinar» y que recorrió de forma generalizada los colegios de la Compañía en un año ya de por sí convulso como aquel del 98 . En particular, adquirió extrema gravedad en Deusto a causa de la reacción de los estudiantes ante las adversas noticias procedentes de las Antillas. Hubo manifestaciones a costa de horas de clase, en uno de los frontones ahorcaron un muñeco que representaba a un marine y prendieron fuego a la bandera de las barras y estrellas. La autoridad académica logró a duras penas mantener el orden, ganado finalmente a base de sanciones y de la nada despreciable cifra de veintiuna expulsiones ${ }^{15}$.

Al siguiente curso académico abandona Deusto y continúa Filosofía en Madrid. Del trauma que supuso el 98 da cuenta una carta de 1904 dirigida a Unamuno. En ella manifestaba que «desearía, pues, que no diera usted la carta mía sino como el estado mental de un muchacho de veinte años, que abrió los ojos de la curiosidad razonadora al tiempo de la gran caída de las hojas de la leyenda patria", a la vez que afirmaba que "si aquí se ha de hacer algo, lo primero es no contar con esos decadentes $" 16$.

\section{PRIMERA REBELIÓN DE LAS MASAS Y WELPOLITIK}

Una vez superada Lengua Árabe, asignatura pendiente del curso anterior, en 1902 obtiene la licenciatura en Filosofía por la Universidad Central de Madrid. Publica sus primeras colaboraciones periodísticas de crítica literaria ${ }^{17}$. Dos años más tarde se doctoró con la tesis Los terrores del año mil. Crítica de una leyenda. Nada mejor para un estudiante de filosofía que desplazarse a Alemania, primera potencia mundial en la materia. Desde abril hasta noviembre de 1905 estudia en la Universidad de Leipzig, donde tuvo «el primer cuerpo a cuerpo desesperado con la Crítica de la razón pura». El siguiente semestre académico estuvo en Berlín. Regresa a España en marzo de 1906. En octubre viaja a Marburgo, en donde permanece hasta agosto de 1907.

\footnotetext{
${ }^{14}$ Ortega, Obras..., vol. I, 535.

${ }^{15}$ SaÉnz de Santamaría, Carmelo, Historia de la Universidad de Deusto (1886-1961). Bilbao, Universidad de Deusto, 1962. págs. 51-53. Revuelga GonZÁlEZ, op. cit, págs. 562-564.

${ }^{16}$ Ortega y Gasset, José, y Miguel de Unamuno, Epistolario completo Ortega- Unamuno. Edición Laureano Robles Carcedo. Madrid, Ediciones El Arquero, 1987. págs. 33-34.

${ }^{17}$ Ortega, Obras..., vol. I, 13-37 págs.
} 
No fue la filosofía el único cometido del viaje. Matriculó cursos, entre otros, de Fisiología, Histología y Anatomía. A Manuel, el pequeño de sus hermanos y estudiante de Ingeniería de Minas, solicitó consejo para «saber matemáticas ${ }^{18}$. En otra ocasión declaró que «tengo que salir de aquí sabiendo por lo menos latín, griego y alemán» ${ }^{19}$. Para alcanzar tales objetivos, aplicó una recia autodisciplina con rigurosos horarios de estudio. No cesaba de pedir libros y periódicos a sus familiares.

A nivel personal, la abundante correspondencia descubre la añoranza por la familia y los amigos. No disimula la animadversión a los hoteles y a la calefacción central. Criticaba la frugalidad de la alimentación, inferior en una tercera parte a la española. A Francisco Navarro le comentó la laxitud de la moral sexual germana, mientras defendía la pericia hispana en la materia. Mostró preocupación por disponer de los recursos económicos con los que afrontar la estancia con cierto desahogo. En numerosas ocasiones ofreció a su padre artículos para El Imparcial en compensación por los gastos originados; le propuso la puesta en marcha de una «biblioteca filosófica semipopular» de obras alemanas e inglesas, advirtiéndole que «no es asunto de ganancia sino patriótico: conque cubra gastos y compense el trabajo, listo ${ }^{20}$.

La vida cotidiana dispuso ante el joven unas costumbres e idiosincrasia novedosas, objeto de una crítica demoledora, de la mofa e, incluso, del insulto. Consideraba a los alemanes inferiores al talento de los españoles. Así en una carta de marzo de 1905 afirmaba que «el secreto alemán está en aprovechar y hacer fecundo a los tontos". A Rosa Spottorno, le decía que «esta tierra y esta gente ya sabes que me son, en el fondo, profundamente odiosas ${ }^{21}$. De entre los distintos aspectos, en concreto le resultaba insoportable el que los alemanes sugiriesen «la imagen de una vida antiestética, abrumada, impersonal. Todos parecían criados y todas criadas. ¡Qué asco! ${ }^{22}$. Por cierto, no fue éste el único desliz hacia un aristocratismo burdo, ajeno a la figura del noble intelectual tan largamente perseguida como teorizada a lo largo de su vida; así, cuando comparó la dieta alemana y española, escribió que la clase miserable puede que «coma menos, pero esa clase no cuenta» ${ }^{23}$.

Estos comentarios, tal vez insignificantes, quizá producto del subconsciente, fuerzan a interrogarse si el consabido elitismo no encuentra su origen en esta temprana etapa. Por supuesto, antes había participado de la exquisitez de la burguesía capitolina y de la excelente formación jesuita, pre-

\footnotetext{
${ }^{18}$ Ibid., pág. 133.

${ }^{19}$ Ibid., pág. 182.

${ }^{20}$ Ortega, Cartas..., págs. 255-257, 273, 284, 400 y 402, 611, 660.

${ }^{21}$ lbid., pág. 449.

${ }^{22}$ lbid., pág. 440.

${ }^{29}$ Ibid., pág. 610.
} 
cedentes nada desdeñables. Pero el reverso al elitismo, que lo completa, esto es, la animadversión a las masas, la percepción de otros muchos de menos calidad, data de la experiencia alemana. El párrafo transcrito más abajo bien pudiera incluirse mutantis muntandi en las primeras líneas de La Rebelión de las masas (1930) y, sin embargo, forma parte de una carta a Francisco Navarro, fechada en Leipzig el 28 de mayo de 1905:

"Los domingos están atestados todos estos jardines y todos los demás restaurantes y cafés de la población. Los sajones necesitan absolutamente -según voy viendo- reunirse una vez a la semana en rebaños, sentirse manada, rodearse de una pesada atmósfera de humo. No tiene $\mathrm{V}$. ni idea de lo pueblo que son: aún no he visto ni un hombre ni una mujer que parezcan señores" ${ }^{24}$.

No se trataba de una mera cuantificación del hecho. Llamaba la atención de su amigo sobre el menoscabo a la individualidad que suponía la masificación social. En otra carta de diciembre de 1906, afirmó que «los alemanes casi en su totalidad y aunque tengan gran saber e inteligencia- son, en cuanto hombres, impersonales, son meros adjetivos"; el fenómeno alcanzaba a una sociedad desarrollada y culta como Alemania. La igualación social no era apreciable en el ámbito cultural de donde Ortega procedía: "La diferencia latina entre señores y hombres... no se advierte aquí: todos van igualmente vestidos y tienen iguales rasgos fisionómicos" ${ }^{25}$. De ahí a la aparición de una temprana defensa del hombre egregio mediarán escasos meses. En junio de 1907 redactó unas líneas que obligan a pensar que el elitismo social, teorizado en la década de los veinte, resultaría de una reflexión continuada:

«La gente, el vulgo que ahoga al hombre enérgico y personal, que no quiere sufrir a nadie ideas propias, que exigen que todos piensen como todos o lo que es lo mismo que nadie piense. Así se ha quedado España reducida a sólo los espíritus vulgares, ciegos, terrenales, débiles. Es un caso trágico de selección al revés» ${ }^{26}$.

La atención prioritaria al estudio y la lectura, junto con la percepción de una sociedad diferente, no impidieron el interés por la política alemana. Alemania alcanzó plena expansión en todos los ordenes. Un intenso nacionalismo recorría el país ${ }^{27}$. La reorientación de la política exterior de Guillemo II tendía a asegurar una mayor presencia en el mundo y un «lugar al sol» en el

${ }^{24} \mathrm{Jbid}$., pág. 609.

${ }^{25} \mathrm{Ibid}$., pág. 610.

${ }^{26}$ ORTEGa, Cartas..., pág. 567.

${ }^{27}$ GUILLEN, Pierre, Historia de Alemania. 2. El Imperio alemán 1871-1918. Barcelona, Editorial Vicens Vives, 1973. págs. 101-103 y 111-266. AbELLÁN, Joaquín, Nación y nacionalismo en Alemania. La «Cuestión alemana» (1815-1990), Madrid, Tecnos, 1997, págs. 99-118. Droz, Jacques, Historia de las doctrinas políticas en Alemania. Madrid, Aguilar, 1971, págs. 112-121. 
reparto colonial del que había salido beneficiados Inglaterra y Francia en la conferencia de Berlín (1884-1885).

Esta atmósfera cargadamente nacionalista e imperialista avivó el interés de Ortega por la política internacional. Empero, los primeros comentarios versan, breve pero significativamente, sobre la guerra ruso-japonesa: «No creo que haya caído entre piedras el ejemplo del Japón", escribió a propósito de un nuevo patriotismo para España ${ }^{28}$. El conflicto, tan ajeno en apariencia a unos ejercicios espirituales en los que al tenor de la correspondencia participó Rosa Spottorno, lo que irritó mucho a Ortega, fue aprovechado para asociar las ideas de pecado y guerra. La teología católica concebía la guerra como un mal, como un castigo al pecado en tanto infracción del orden divino. Al respecto, en una carta de marzo de 1905, Ortega preguntaba a su novia: " ¿...aunque se tenga más fe que San Pedro de qué un pecado venial que tú cometas puede salvar o dejar de salvar 50.000 rusos y japoneses? ${ }^{29}$. El interrogante cuestionaba la conexión entre orden religioso e internacional en el contexto de unas prácticas de piedad habituales en España.

La importancia que asumiría en el futuro la política internacional quedó apuntada cuando, al comentar la crisis de los parlamentos, proponía que el Congreso se erigiera en promotor de la enseñanza y «despertador a la política internacional»; con ello, se evitaría el «empirismo» de la política europea ${ }^{30}$. Insistió a su padre en «hablar mucho de política y más que nada de Weltpolitik o política internacional: es un asunto este en que quiero ir orientándome para futuros proyectos» ${ }^{31}$. Ese declarado interés le impulsó a rebasar la privacidad de la correspondencia y redactar un conjunto de artículos para El Imparcial. En “La política de Guillermo $11{ }^{32}$, de marzo de 1905, ilustraba la dirección nacionalista con frases como «Alemania es una avenida de paz gracias al poder de los ejércitos alemanes», del canciller Bulöw, o «el Imperio alemán se ha convertido en un imperio universal», de Guillermo II. El segundo artículo, titulado «Notas de andar y ver. Berlín Balada Marcial» ${ }^{33}$, de septiembre de 1905, es una extensa metáfora en torno a la simbología nacionalista representada por la cuadriga de la Victoria sobre la Puerta de Brandenburgo y la parafernalia militar de la Gran Parada de otoño que, al tenor del texto, hubo de presenciar in situ. En «Notas alemanas. Congreso de las Walquirias», de octubre de 1905, aludía al orgullo nacional de los alemanes e ironizaba sobre las demandas feministas de una Dieta de Señoras Progresistas en Berlín. Por último, en «Anarquía gubernamental» sostuvo que «siempre el régimen de unos pocos será injusto pero no está dicho que sea siempre un mal gobierno» ${ }^{34}$.

\footnotetext{
${ }^{28}$ ORTEga, Cartas..., pág. 659.

29 /bid., pág. 327.

${ }^{30}$ Ibid., págs. 649-650

${ }^{31}$ Ibid., pág. 179.

32 lbid., pág. 125-127.

${ }^{33}$ ORTEGA, Cartas..., pág. 160-166.

${ }^{34}$ Ibid., págs. 289-294.
} 
Lamentablemente, ninguno de estos textos se publicaron. No sería por una falta de empeño que le enfrentó a su padre, a la sazón director del periódico. Al principio trató de restar importancia a la evidente decepción de ver inéditos sus primeros trabajos, máxime en quien como él pertenecía a una saga de notables periodistas. Pero al final planteó a su padre abiertamente: "conque dime si no te parecen bien mis notas y porqué: con objeto de mejorarme y enmendarme ${ }^{35}$.

Por suerte, un viaje de Alfonso XIII a Alemania en noviembre de 1905 cambió las cosas. Ese año y a principios del siguiente, el Rey visitó París, Londres, Munich, Berlín y Viena. Con ello pretendía conocer directamente las naciones del mismo entorno diplomático, procurar el entendimiento sobre Marruecos - la Conferencia de Algeciras transcurrió de enero a abril de 1906-y solucionar el matrimonio real -el 31 de mayo se celebró la boda ${ }^{36}$. La presencia real brindó a Ortega la oportunidad no sólo de cubrir el evento para El Imparcial, sino también relacionarse personalmente con los protagonistas de aquel encuentro. En las cartas, Ortega ridiculiza al Monarca: «he visto con mis ojos el azoramiento del Rey en el andén: no sabía el pobre ni como saludar». Tras la recepción a la prensa en la Embajada de España, donde el Canciller Von Bülow le felicitó por sus progresos en alemán, escribió que Alfonso XIII no le ha dicho nada interesante, «lo único que está bien de cuanto hace y dice es el ruido de una espuela contra otra al cuadrarse para saludar»; presentía que el Canciller y compañía estarían asombrados de la «imbecilidad de los que acompañan al Rey». En fin, en otra carta a su madre calificó literalmente al Rey de majadero ${ }^{37}$.

Opiniones poco delicadas que, sin embargo, no expresó en los artículos publicados. Entre el 10 y 17 de noviembre de 1905 publicó anónimamente los cinco siguientes: «Notas de Berlín. La llegada del Rey», "Notas de Berlín», «Notas de Berlín. Una función de gala», «Notas de Berlín. El Rey de España en Alemania», "Notas de Berlín» ${ }^{38}$. Los lectores del periódico supieron entonces de la entusiasta acogida de los berlineses al monarca español, con las calles adyacentes a la imponente avenida Unter den Linden abarrotadas de público. Un despliegue espectacular, propio de la parafernalia prusiana, servía de marco incomparable a la regia visita. Poco después, completaba la serie con «Notas de Berlín. Escuadra y bendición de San $\mathrm{Pe}$ dro" ${ }^{39}$, de 14 de enero de 1906, sobre la intervención del canciller Bulöw en el Reichstag en demanda de créditos para incrementar la flota con la que

${ }^{35}$ Ibid., pág. 203.

- ${ }^{36}$ CALDUCH Cervera, Rafael (coord.), La política exterior española en el siglo XX. Madrid, Ediciones de las Ciencias Sociales, 1994. págs. 27-28. JOVER Zamora, José María, España en la política internacional. Siglos XVIII- XX. Madrid, Marcial Pons, 1999. págs. 183-184.

${ }^{37}$ Ortega, Cartas..., págs. 214, 215, 216, 219.

${ }^{33}$ Ibid., págs. 690-706.

3o Ibid., págs. 706-710. 
garantizar la presencia alemana en el mundo y que constituyó uno de los objetivos primordiales de la política imperial.

Tanto la correspondencia como los artículos que conforman la primera producción política de Ortega, transmiten la presencia asfixiante de la política nacionalista y, en particular, del emperador en la sociedad germana. Ya en su primera carta firmaba con un irónico «Kaiser Pepe». Luego desplegará un repertorio de imágenes dedicados al emperador, siempre con un tono burlón: «mirobolante y múltiple Guillermo el Segundo», «Don Guillermo de la Mancha o Don Lohengrin protector de la Elsa comerciante alemana", "César sobre un caballo castaño», «Guillermo II el Sorprendente» y «el cargante del Káiser». Una segunda idea es la percepción de una Alemania en un momento de «sobrecrecimiento nacional», florecimiento económico e influencia moral en el mundo. Prepotencia que contrasta con el ambiente decadente en España, «una pobre vieja que vive emparedada en el Reloj de la Puerta del Sol».

Por todo ello, no le sedujo la política alemana, pero aceptó el método por el que Alemania se había hecho nación:

«Alemania no puede representar para nosotros una dirección política; de otras partes somos requeridos. Pero en cambio Alemania es precisamente la nación cuya influencia en la dirección moral e intelectual nuestra habrá de sernos más fecunda. Los ingleses son ingleses, los franceses son, como decía Cánovas, «españoles con dinero", los alemanes no son alemanes, se han hecho alemanes en cincuenta años. He aquí lo que nosotros tenemos que aprender en Alemania y sólo aprenderemos en ella: el modo de hacernos españoles en poco tiempo, el gran secreto alemán, el método. La instrucción pública es el resorte de ese secreto ${ }^{40}$.

La condena general a la política alemana encuentra en el socialismo una excepción. Del temprano interés por este tema dio cuenta en «Notas de Alemania. Babel, Bibel y Bebel» ${ }^{41}$, aparecido en El Imparcial el 27 de octubre de 1905. El artículo relata la Dieta celebrada el mes anterior en Jena por el Partido Socialdemócrata en la que se acordó, a propuesta de Rosa Luxemburgo, la utilización de la huelga en demanda del sufragio universal. Describe, además, otra reunión de economistas en Maunheim, donde discutieron sobre la libre concurrencia o la intervención legislativa del Estado en los carteles industriales ${ }^{42}$.

Una razón que pudiera explicar la atracción de Ortega por la socialdemocracia alemana fue la presencia de intelectuales en sus filas, los "socialistas de cátedra», a diferencia del socialismo español anterior al «viraje intelec-

\footnotetext{
${ }^{40}$ Ortega, Cartas..., pág. 701.

${ }^{41}$ lbid., págs. 686-689.

${ }^{42}$ GuILLÉN, op. cit. págs. 199-201.
} 
tual». Por otra parte, los maestros de Ortega en Marburgo, en particular Cohen, participaron en la polémica revisionista que tuvo en Kautsky y Bernstein a sus representantes antagónicos. Los neokantianos impugnaron frente a la ortodoxia marxista el determinismo histórico, la necesidad dialéctica que conduce inevitablemente a la sociedad sin clases, y agregaron un fundamento ideal, en relación directa con el imperativo categórico kantiano, que contradecía abiertamente las relaciones estructura-superestructura ${ }^{43}$. De tal manera pudo conocer una alternativa teórica al dogmatismo marxista; Kant inspiraba el socialismo alemán. Aunque Ortega no participó en este debate, hubo de conocerlo y se limitó a dejar constancia de la simpatía por un socialismo no marxista. El 11 de noviembre de 1906, al poco de llegar a Marburgo, escribía estas líneas a su novia:

«El liberalismo era algo cuando no existían libertades políticas: ganar éstas era su destino. Hoy el liberalismo tiene que ser más que liberal, mucho más: por ej. socialista. Esto soy no por las razones que suelen llevar el pensamiento al socialismo, sino porque creo que sólo en él serán posibles de un lado las libertades íntimas, de otro las virtudes viriles» ${ }^{44}$.

En consecuencia, el liberalismo era la referencia última. El socialismo resultaba un plus añadido históricamente a aquel para el progreso político y social. Cuando describe a su novia su participación en una «romántica» reunión de simpatizantes socialistas, celebrada en Marburgo a primeros de febrero de 1907, destacando la presencia de Guillermo Ferrero, no menciona a Marx. Sin embargo, Ortega subraya la aversión del socialismo al nacionalismo al señalar que "aquellos hombres sienten un hondísimo desprecio por todo lo alemán, entiende bien, por todo alemanismo". Eran los socialistas «espíritus libres del horrendo prejuicio nacional, del horrendo prejuicio de las religiones positivas » ${ }^{45}$. Tanto marxismo como revisionismo quedaban lejos de la zona de intereses del joven Ortega; el socialismo interesa como perfección del liberalismo y recusación al nacionalismo.

\section{DE LA NACIÓN KANTIANA AL COSMOS EUROPEO}

Una opinión diversa de la sociedad y política alemanas le mereció la cultura. No disimuló nunca su admiración por esta otra cara de Alemania, a la que calificó de «máquina intelectual» ${ }^{46}$ y de «una tierra ideal para la razón» ${ }^{47}$. Dentro de este tributo general, destacó una institución: «lo que es

\footnotetext{
${ }^{45}$ Ruiz Miguel, Alfonso, «La socialdemocracia» en Fernando VAllespín, Historia de la Teoría política. Madrid, Alianza Editorial, 1992. Vol. IV, págs. 219-225.

* ORTEga, Cartas..., pág. 476.

${ }^{45}$ lbid., pág. 519.

${ }_{46} \mathrm{Ibid}$., págs. 227-230.

${ }^{47}$ lbid., págs. 247- 248.
} 
prodigioso es el concepto de Universidad que aquí tienen " ${ }^{48}$. Fruto de ello fue la serie de seis artículos escritos para El Imparcial, entre el 16 de enero y el 20 de febrero de 1906, bajo el título «La Universidad alemana y la Universidad española" ${ }^{49}$, en los que explicaba su impecable organización y funcionamiento. Antes afrontó en un extenso exordio la relación entre déficit pedagógico y decadencia nacional. No era una mera cuestión técnica sobre planes de estudio, sino algo más profundo en conexión con el denominado problema de España. Sabedor del lema «despensa y escuela» de Joaquín Costa, Ortega avanzará en este terreno hacia la pedagogía social en deuda con Paul Natorp, neokantiano de Marburgo.

En el segundo artículo, publicado el 23 de enero de 1906, sostuvo que España debió ser en la edad moderna la «Grecia cristiana», en vez de desparramar la fuerza nacional en empresas imperiales. Con cierto regusto ganivetiano, el de «lo español puro» teorizado en el Idearium Español, asegura que «el traje de potencia mundial nos estorba para la labor de hacernos a nosotros mismos». Según Ortega, la decadencia no trae causa en una agresión externa, sino por una depresión de nuestro ánimo, explicación contraria a la dominante en España que imputaba la culpabilidad en este terreno a Francia e Inglaterra. Pero España, afirma, clamaba por la cultura y la europeización y la Universidad será su instrumento más importante. A tal efecto, propugna fijarse en la Universidad alemana, sin imitarla, pues «sólo españolizando lo europeo" se logra el doble objetivo de regenerar y europeizar el país activamente. A.lemania y su Universidad constituyen un ejemplo formal, no de fondo.

Los artículos sobre la universidad, y las precedentes crónicas del viaje de Alfonso XIII ganaron la confianza de su padre, remiso hasta entonces a darle cabida en el periódico. A lo que habría que sumar el prestigio de haber estudiado un año en Alemania, de donde regresó en marzo de 1906. Como quiera que el padre fuese nombrado mantenedor de los juegos florales de Valladolid, y para aligerarse de la gran cantidad de trabajo, encargó la redacción del discurso a su hijo. El Norte de Castilla del 2 de octubre anunciaba la llegada de Ortega Munilla acompañado, entre otros, de «su hijo el notable literato don José Ortega Gasset». Al día siguiente, el diario vallisoletano y El Imparcial publicaron la intervención, pero de su lectura se colige que el despliegue filosófico empleado no podía proceder sino de Ortega ${ }^{50}$. En efecto, el análisis de la situación de España, sobre el que gira la intervención, comienza con la mención de los Discursos a la nación alemana de Fitche, a quien sigue Nietzsche y, encubiertamente, Kant; sólidas bases sobre las que Ortega cuestiona el viejo patriotismo: «Teníase, pues, de patria

\footnotetext{
${ }^{48}$ Ibid., págs. 247- 248.

${ }^{49} \mathrm{Jbid}$., págs. 711-746.

${ }^{50}$ ORtega, Cartas..., pág. 747-776.
} 
una noción externa, objetiva, plástica, comparativa y por patriotismo se entendía no más que una vago y ampuloso sentimiento de admiración retórica» ${ }^{51}$. Esta idea históricamente quebró en el 98 y pierde su carácter exclusivo e inmejorable al contraste con otros patriotismos análogos. Late en el discurso la propia experiencia de Ortega en Alemania cuando, al invocar un cosmopolitismo viajero, cita con propiedad a Cervantes: «luengas peregrinaciones hacen a los hombres discretos». Pero lejos de superar el nacionalismo, Ortega lo reafirma al forzar un cambio:

"Ahora patria es algo íntimo, que llevamos cada uno dentro, que anima todos nuestros pensamientos, quereres, dolores y ensueños; la patria no es algo objetivo, algo que está fuera de nosotros: la Patria está en nosotros vayamos donde vayamos $\gg$.

La introspección de la idea nacional en la conciencia individual malogra paradójicamente el cosmopolitismo del que parte para superar aquella noción externa de patria; el sujeto portador de esa idea advierte que «el resto de los otros pueblos que visita le ofrecen un algo hostil e impenetrable», irreductible nacionalismo opuesto a una sincera ciudadanía del mundo. En el traslado de la nación desde la externalidad a la intimidad, Ortega ha enclaustrado la idea "patria» o «nación» en el sujeto que la piensa. Esta construcción de la nación-en-mi se auxilia del idealismo kantiano, estudiado a fondo en su primer año en Alemania y del que confesará, años después, haberse sentido preso. Para Ortega, «Kant es un clásico de este subjetivismo nativo propio del alma alemana» por el que hace vivir al sujeto «recluso dentro de sí mismo, y este «sí mismo» es la única realidad verdadera» ${ }^{53}$.

La idealización de la nación, en el sentido expuesto, encadena sucesivamente las ideas capitales del nacionalismo orteguiano. En primer lugar, surge un patriotismo individualista: «De esta suerte el patriotismo mana de lo más adentrado de las entrañas y del grumo más hondo, más personal de nuestra conciencia ${ }^{54}$. En segundo lugar, el yo orteguiano conoce y legitima la nación, un punto partida muy kantiano ciertamente, pero aceptado con reservas: el cosmopolitismo es un primer intento para rescatar la idea «nación" de la conciencia individual y facilitar la salida al exterior, intento frustrado porque la idea nacional intimada colisiona con otras de igual carácter, produciéndose recíprocas hostilidades; sin embargo, la aristocracia intelectual libera la idea nacional de la conciencia individual, erigiéndose en conciencia colectiva, jerarquizada, la expande socialmente y legitima: «este

${ }^{51}$ Ibid., pág. 750.

${ }^{52} \mathrm{Ibid}$., pág. 752.

${ }^{53}$ ORTEGA, Obras..., vol. IV, págs. 25-39.

${ }^{54}$ Ortega, Cartas..., pág. 752. 
nuevo patriotismo hay que reconocer que no existe sino en unos pocos españoles: supone cierta reciedad en el ánimo, cierta agilidad del intelecto ${ }^{55}$. Así, el nacionalismo liberal y elitista de Ortega quedó formulado en 1906.

Aparecerá también en esta reflexión el vitalismo, optimismo y voluntarismo nietzscheniano y una repulsa del pesimismo político. Pero el tono kantiano del discurso reaparece al formular los dos imperativos de la nueva moral nacional: uno, socializar el país en el sentido de recuperar las virtudes públicas, la primera de ellas la honradez; otra, la participación en la política porque «nada de cuanto acontece en mi país puede serme indiferente». Las propuestas tras el Desastre de industrializar, descentralizar, importar leyes e instituciones, constituyen extranjerismo, imitación. El problema capital es la elevación de la cultura del país mediante la educación.

A pesar de la espesura del discurso, inapropiada para unos juegos florales, El Norte de Castilla de 3 de octubre relata que fue escuchado con atención, «interrumpido muchísimas veces por salvas nutridísimas de aplausos» y lo calificó curiosamente como «obra en que la pluma primorosa del literato ha sido guiada por el talento clarísimo del pensador".

En conexión con el problema nacional, Ortega aborda la concepción de la Historia, tan importante para la formación de las ideas nacionales e internacionales. Planteado el problema nacional en términos estrictamente culturales los actores llamados a la regeneración habrían de ser lógicamente los intelectuales e historiadores. Debían reescribir la historia. Ésta adquiere un claro propósito nacionalizador cuando afirma que «las cuatro o cinco veces que Alemania se ha reconstituido lo ha hecho bajo la moción de un nuevo libro de historia y de un historiador». Ello no significa ruptura con el pasado ni imitación ya que «no es posible que un pueblo renazca dejando tras sí una solución de continuidad consigo mismo ${ }^{56}$. Una historia inédita orientada no sólo a la regeneración interna de la nación; también para dar a conocer y proyectar una imagen real del país en el mundo, "para imponer al extranjero una interpretación española de España y acabar de una vez con la idea negra que se tiene tras los montes de ella» 57.

No hubiera extrañado el que Ortega cediera a un nacionalismo extremo. En alguna ocasión se manifestó en este sentido, como en una carta que envió a su padre desde Berlín en septiembre de 1905. En ella optaba por la "españolización de España» frente a su «europeización». Fue, sin embargo, una excepción. La citada carta homenajeaba el pensamiento de su amigo Navarro Ledesma, fallecido entonces, y de quien destacó la propuesta de guerra de independencia del pensamiento español contra el «extranjeris-

${ }_{55}^{5}$ lbid., pág. 752.

${ }^{50} \mathrm{lbid}$, págs. 652-653.

${ }^{57} \mathrm{lbid}$., pág. 232. 
mo". Al contrario, declararía que "cada vez odio más el nacionalismo que me parece una forma de religión positiva. Hay que romper las lindes de hierro que encuadran las naciones y, en su lugar, hacer pueblos "58.

Acorde con esa condena al nacionalismo, mostró una gran receptividad a otros países y culturas europeos. Elogió por encima de todos la alemana. Pero el dominio de Alemania en el campo del pensamiento, de las ciencias y de la técnica, no excluyó el reconocimiento de lo inglés porque "es estéticamente considerado superior siempre a lo alemán. Lo alemán, en cambio, es más sabio ${ }^{59}$. Insistió en viajar a Italia. Las referencias a la cultura francesa decrecen, como quien pretende superar una etapa de influencias.

La adscripción a una identidad colectiva de carácter nacional (término éste último que sustituirá arbitrariamente por «pueblo» 0 «raza»), de una parte, y la condena al nacionalismo junto a la prédica de un cierto cosmopolitismo, de otra, culminan el dinamismo de las ideas internacionales del primer Ortega. Próximo al regreso, el 23 de junio de 1907, escribía que «tenemos que hacer una vida cosmopolita aunque siempre afirmados en nuestra España» ${ }^{60}$. Inmediatamente después, el 5 de julio de 1907, cuando proyectaba un viaje con su novia, insistía que «nuestro viaje a Italia nos ofrece asimismo otra corrección de la conciencia histórica; la noción de humanidad que nos da nuestro pueblo es preciso enriquecerla con la que otras razas nos da $" 61$.

Sobre estas cuestiones no es erróneo afirmar que en Alemania manejó Sobre la paz perpetua e Ideas para una historia universal en clave cosmopolita, opúsculos en los que Kant formulaba la instauración de una federación de Estados (sucedáneo de un inalcanzable Estado mundial), bajo las normas del Derecho Internacional en orden a garantizar la paz y la seguridad, a semejanza de la sociedad civil producto del contrato social. Sin embargo, Ortega no orienta su reflexión hacia estas ideas de elaboración política o jurídica. Leyendo Sobre la paz perpetua, cuando versa sobre la hospitalidad universal, Kant parece asentir a nuestra tesis: "Se trata en este artículo, como en los anteriores, de derecho y no de filantropía» ${ }^{62}$.

En buena medida Ortega sí enlaza con el talante de los viajeros españoles del XVIII, aunque los ilustrados dirigían su reforma hacia el interior del país, doméstica como era en su perspectiva y finalidad. Cuando traspasaban la frontera, aquellos hombres se volvían fríos y acríticos ${ }^{63}$. La potencia aleccionadora del viaje, para reformar y enriquecer el país, mediante el co-

${ }^{58}$ Ortega, Cartas..., pág. 515.

${ }^{59}$ lbid., pág. 451.

${ }^{60}$ lbid., pág. 563.

${ }^{61}$ Jbid., pág. 573.

${ }^{62}$ KANT, Immanuel, Sobre la paz perpetua. Madrid, Tecnos, 1998. p. 27.

${ }^{63}$ GÓMEZ DE LA SERNA, Gaspar, Los viajeros de la llustración. Madrid, Alianza Editorial, 1974. págs. 1115 y $71-106$. 
nocimiento de la realidad foránea, constituye la diferencia más notable entre Ortega y nuestros ilustrados. Más cercanas en el tiempo, tampoco pueden ignorarse las influencias de la generación del 98 , cuyos componentes viajaron y recrearon el paisaje, principalmente el castellano.

El cosmopolitismo orteguiano, apenas diseñado a leves trazos, por ello abierto y contradictorio, se explica al relacionarlo con las ideas internacionales de esta primera etapa. Asume la defensa de un cosmopolitismo con un objetivo nacional, lo cual constituye una evidente paradoja: reafirmar la propia identidad al contraste con la realidad exterior. Y, por si fuera poco, con una utilidad reformadora y potenciadora de la realidad nacional, relegando el concepto de humanidad a un segundo plano.

Si por una parte el cosmopolitismo deviene en una actitud intelectual con un propósito reafirmativo de la nación, por otra adolece de etnocentrismo. La ciudadanía del mundo queda dos veces desvirtuada. Ortega contactó física e intelectualmente con los países europeos, realidades extrañas a la española que detentaban una indudable posibilidad de identidad colectiva por encima de la diversidad. Además, el debate entre casticismo-europeísmo apasionó a nuestra intelectualidad. Ganivet, Unamuno y Costa habían contribuido respectivamente con Idearium español, En torno al casticismo, ambas en 1897, y Reconstitución y europeización de España. Programa para un partido nacional en 1900. El primero de ellos apostará por el aislamiento y el regreso a un españolismo introvertido. Costa y Unamuno abrirán el país a Europa.

Que Ortega leyó y reflexionó sobre las obras citadas parece incuestionable. El Idearium fue objeto de algún solapado elogio en la correspondencia a su amigo Navarro Ledesma, confidente y estudioso de Ganivet ${ }^{64}$. En septiembre de 1905, Ortega lamentará profundamente la muerte de Navarro Ledesma a quien considera junto con Ganivet los «dos más hondos españoles». En aquel momento calificará la europeización de España como «una burrada que sólo se les ocurre a los horteras". En definitiva, Navarro significaba la «guerra de independencia del pensamiento español» contra el extranjerismo, lo cual era inteligible únicamente en clave ganivetiana ${ }^{65}$.

A Costa, adalid de la recuperación del nivel con Europa para regenerar el país, le reprocharía la ausencia en su programa de una definición de Europa, «porque aquí la gente cree que Europa es ferrocarriles y sport» ${ }^{66}$. Pero fue Unamuno con quien más se carteó sobre la cuestión. Una carta de 30 de mayo de 1906 advierte un encuentro poco pacífico entre ambos. El rector de la Universidad de Salamanca confesaba que "yo me voy sintiendo furiosa-

\footnotetext{
${ }^{64}$ Ortega, Cartas..., pág. 602 y 644.

${ }^{65}$ Ibid., págs. 173-176

${ }^{66}$ /bid., pág. 674.
} 
mente anti- europeo» y, con vehemencia agregaba "¿qué ellos inventan cosas? ¡Invéntenlas! La luz eléctrica alumbra aquí tan bien como donde se inventó" $" 67$. En efecto, en aquellos instantes Unamuno había culminado una transición desde las tesis europeístas y cientificistas, defendidas en En torno al casticismo, a posiciones contrarias vertidas en Vida de Don Quijote y Sancho $(1905)^{68}$.

Por el contrario Ortega, quien considera a Unamuno un «hombre sobreespañol», propone superar el aislamiento e incorporar España a la cultura universal. Desarrolladas en un ámbito cultural, estas ideas tienen implicaciones políticas. En una carta fechada el 30 de diciembre de 1906 dice que siente vergüenza «pensar que hace siglos mi raza vive sin contribuir lo más mínimo a la tarea humana" y que "sólo habrá cultura española cuando algunos españoles hagan cultura universal»,69. El joven pensador propone, primero, entrar en la cultura europea y, segundo, despreocuparse «como de nuestro yo, de la España actual». Una cultura nacional a priori en momentos de decadencia, afirma, nace muerta. En efecto, toda cultura universal y eterna viene a ser cosmopolita en tanto válida para todos los países. Pero Ortega no puede ocultar su etnocentrismo cuando concluye que esa cultura que reclama es de Europa, «la flor del Universo».

\section{CONCLUSIONES}

Ortega percibió en el ambiente familiar los conflictos coloniales de fin de siglo. Las experiencias públicas de los Gasset y, principalmente, El Imparcial constituyen las fuentes de sus primeras ideas internacionales. Con los jesuitas memorizó la idea providencialista de la historia y la esencia católica de España; mostró entusiasmo por la literatura colonial; escuchó la descripción de las misiones jesuitas. El Desastre arrumba la idea de una nación irreal producto del patriotismo grandilocuente y, en su aspecto exterior, pone al corriente a toda una generación de la verdadera potencialidad de España. Realidad que contrastó bruscamente con la pujante Alemania de la que supo en sus viajes de estudios. Alemania ofrecerá un método para regenerar su propio país: el rigor de la ciencia, en particular, la toma de conciencia a través del pensamiento, la recuperación de la continuidad nacional mediante la historia y la acción pedagógica dirigida a la reforma social. Una actitud que excluía el mimetismo, la política nacionalista y una sociedad, aun culta, masificada.

Esta primera etapa consagra a Ortega como un nacionalista liberal e incipientemente elitista, esforzado en sliperar el patriotismo confesional y re-

\footnotetext{
${ }^{67}$ Ortega, Epistolario.., pág. 42.

${ }^{6}$ MenÉndez Alzamora, Manuel, «El pensamiento político español del siglo XX» en Vallespin, Historia.. Tomo VI. págs. 464-467. Una tesis matizada en Beneyto, José María. Tragedia y Razón. Europa en el pensamiento de español del siglo XX. Madrid, Santillana, 1999. págs. 113-123.

${ }^{69}$ Ortega, Epistolario... págs. 55-61.
} 
tórico de la Restauración; a la vez, condena el nacionalismo extremo. Las experiencias coloniales no le merecen una condena ética, sí una impugnación por conveniencia de los negativos resultados bélicos como «exteriorización» de la incompetencia nacional; cierto que condenó, después, el imperialismo germano. Apuntó un cosmopolitismo de disposición viajera y corte intelectual, amén de utilitario, accidental y subordinado al nacionalismo español, sin débito alguno para Kant. Cuando propugna la independencia del pensamiento español y rechaza la europeización, en la línea de Ganivet y Navarro Ledesma, lo hace en el contexto desfavorable por la muerte del último de ellos. La generación de Unamuno, dentro del debate europeísmo- casticismo, nutre la opción europeizadora de Ortega. La difícil síntesis europeísmo-cosmopolitismo deriva de la creencia en Europa como única capaz de imponer una cultura cosmopolita y clásica, válida para todos los países y tiempos.

Aparecen contradicciones explicables en tanto el pensamiento de Ortega se encuentra fase embrionaria, sometido a evolución, sin sistema. Ideas dispersas en una correspondencia escrita en función de los estados de ánimo y de sus destinatarios, en artículos de periódico publicados con timidez, cuando no bajo el anonimato y la censura paterna. La superposición de los distintos planos de las ideas y las licencias léxicas no extrañan. La juventud le hace receptivo a todas las influencias intelectuales, no siempre armonizables. Pero los grandes temas y preocupaciones internacionales del pensador quedan anotados, dispuestos a ulteriores desarrollos. 